\title{
Peripheral Adaptation Codes for High Odor Concentration in Glomeruli
}

\author{
Jérôme Lecoq, ${ }^{1,2,3 \star}$ Pascale Tiret, ${ }^{1,2,3 \star}$ and Serge Charpak ${ }^{1,2,3}$ \\ ${ }^{1}$ Institut National de la Santé et de la Recherche Médicale, U603, ${ }^{2}$ Centre National de la Recherche Scientifique, UMR 8154, and ${ }^{3}$ Laboratory of \\ Neurophysiology and New Microscopies, Université Paris Descartes, 75006 Paris, France
}

\begin{abstract}
Adaptation is a general property of sensory receptor neurons and has been extensively studied in isolated cell preparation of olfactory receptor neurons. In contrast, little is known about the conditions under which peripheral adaptation occurs in the CNS during odorant stimulation. Here, we used two-photon laser-scanning microscopy and targeted extracellular recording in freely breathing anesthetized rats to investigate the correlate of peripheral adaptation at the first synapse of the olfactory pathway in olfactory bulb glomeruli. We find that during sustained stimulation at high concentration, odorants can evoke local field potential (LFP) postsynaptic responses that rapidly adapt with time, some within two inhalations. Simultaneous measurements of LFP and calcium influx at olfactory receptor neuron terminals reveal that postsynaptic adaptation is associated with a decrease in odorant-evoked calcium response, suggesting that it results from a decrease in glutamate release. This glomerular adaptation was concentration-dependent and did not change the glomerular input- output curve. In addition, in situ application of antagonists of either ionotropic glutamate receptors or metabotropic $\mathrm{GABA}_{\mathrm{B}}$ receptors did not affect this adaptation, thus discarding the involvement of local presynaptic inhibition. Glomerular adaptation, therefore, reflects the response decline of olfactory receptor neurons to sustained odorant. We postulate that peripheral fast adaptation is a means by which glomerular output codes for high concentration of odor.
\end{abstract}

\section{Introduction}

In the vertebrate nasal epithelium, volatile odorants bind to odorant receptors (Buck and Axel, 1991) located in the cilia of olfactory receptor neurons (ORNs). There, they trigger a G-protein-coupled cascade (Jones and Reed, 1989; Bakalyar and Reed, 1990) that leads to the production of intraciliary cAMP and the opening of cyclic nucleotide-gated channels (CNG) (Nakamura and Gold, 1987) permeable to $\mathrm{Na}^{+}, \mathrm{K}^{+}$, and $\mathrm{Ca}^{2+}$ (for review, see Pifferi et al., 2006; Kleene, 2008). $\mathrm{Ca}^{2+}$ plays dual excitatory and inhibitory roles (Matthews and Reisert, 2003). It depolarizes ORNs and activates $\mathrm{Ca}^{2+}$-sensitive chloride channels which allow an efflux of chloride to further depolarize ORNs (Lowe and Gold, 1993). It also triggers several negative feedback processes that underlie adaptation to repeated or prolonged odor activation. $\mathrm{Ca}^{2+}$-binding proteins such as $\mathrm{Ca}^{2+} /$ calmodulin decrease the sensitivity of CNG channels (Kurahashi and Menini, 1997) but also trigger cascades leading to the hydrolysis of cAMP

\footnotetext{
Received Dec. 30, 2008; revised Feb. 3, 2009; accepted Feb. 8, 2009.

This work was supported by the Institut National de la Santé et de la Recherche Médicale, the Ministère de I'Education Nationale, de la Recherche et de la Technologie (Grant NIC0025), the Centre National de la Recherche Scientifique, the Fondation pour la Recherche Médicale (Grant ICP20001222128), the Région lle de France (Sesame Program), the Fondation Bettancourt Schueller, and the Human Frontier Science Program Organization. J.L. was supported by a fellowship from the Fondation pour la Recherche Médicale (Grant FDT20070910324), and P.T. was supported by a fellowship from the Association Française contre les Myopathies (Grant 12411). We thank Jonathan Bradley for his critical comments.

* J.L. and P.T. contributed equally to this work.

Correspondence should be addressed to Serge Charpak, Institut National de la Santé et de la Recherche Médicale, U603, Laboratory of Neurophysiology, 45 rue des St Pères, 75006 Paris, France. E-mail: serge.charpak@ parisdescartes.fr.

DOI:10.1523/JNEUROSCI.6187-08.2009

Copyright $\odot 2009$ Society for Neuroscience $\quad$ 0270-6474/09/293067-06\$15.00/0
}

(Borisy et al., 1992; Yan et al., 1995) or the inhibition of adenylyl cyclase (Wei et al., 1998; Leinders-Zufall et al., 1999). These processes have been extensively analyzed in vitro (for review, see Bradley et al., 2005; Kleene, 2008), whereas in vivo, only one group reported measurements of ORNs activity and adaptation of firing (Duchamp-Viret et al., 2000, 2003).

Furthermore, less is known about the consequences of peripheral adaptation in perceptual habituation or desensitization, an everyday experience in olfaction (for review, see Wilson and Linster, 2008). In the first and second relays of olfaction, i.e., in the olfactory bulb and the pyriform cortex, neurons do adapt (Wilson, 1998; Sobel et al., 2000; Schafer et al., 2005); however, the precise role of ORN adaptation versus local network processing in the decrement of central neuron responses is unclear. Here, we have simultaneously recorded the activation of the presynaptic and postsynaptic compartments of olfactory bulb glomeruli to investigate under which conditions peripheral adaptation can be detected and how it affects the spatial maps of activated glomeruli (for review, see Mori et al., 2006; Wachowiak and Shipley, 2006). Such maps vary with the odorant concentration and are temporally dynamic (Spors and Grinvald, 2002; Spors et al., 2006; Schaefer and Margrie, 2007). We report that under high odorant concentration, ORN adaptation participates to the spatial redistribution of active glomeruli.

\section{Materials and Methods}

Animals preparation, electrophysiological recordings, and two-photon imaging. Wistar rats (29 postnatal day 30-70) were anesthetized with urethane $(1.65 \mathrm{~g} / \mathrm{kg}$, i.p.) and held in a standard stereotaxic apparatus. Olfactory bulb surgery, local field potential recordings, and focal pressure applications of drugs were performed as described previously 
(Chaigneau et al., 2007). NBQX (2,3-dihydroxy-6-nitro-1,2,3,4-tetrahydrobenzo[f] quinoxaline-7-sulfonamide; $250 \mu \mathrm{M}), \mathrm{D}$-APV [D-2-(-)amino-5-phosphonopentatoic acid; $500 \mu \mathrm{M}$ ], and CGP35348 [(3-aminopropyl(diethoxymethyl) phosphoninic acid; $1-10$ $\mathrm{mm}$ ] were obtained from Tocris Bioscience. The temperature of the animal was maintained at $37^{\circ} \mathrm{C}$ with a feedback-controlled heating blanket (Harvard Apparatus). For all experiments, breathing frequency was monitored through a pneumogram transducer (BIOPAC Systems). Olfactory nerve terminals were labeled with $\mathrm{Ca}^{2+}$ green 1 dextran, $10 \mathrm{kDa}$ (Invitrogen), 2-8 $\mathrm{d}$ before experiments using the method developed by Wachowiak and Cohen (2001). Images from subregions of the field of view were acquired at rates up to 20 frames per second using a custom-built two-photon laser-scanning microscope (TPLSM).

Olfactometer. Odorants were applied for $4 \mathrm{~s}$ with a custom-built olfactometer. The olfactometer delivered a constant flow of humidified air in a small teflon reservoir surrounding the rat snout. All tubes connecting the odorant reservoir to the snout were made of teflon to minimize odorant contamination. Odorants used were aldehydes and esters. Two flow meters (Aalborg), one in the clean air path and one before the odorant reservoir, allowed to control odorant concentration in a reproducible manner. To reveal adaptation, high odorant concentrations were used, i.e., from $3-100 \%$ when expressed in percentage of saturated air.

Intertrial alignments of $\mathrm{Ca}^{2+}$ or local field potential responses using respiratory movements. Respiration monitoring revealed spontaneous variations of inhalation frequency. Although minor, they affected the intertrial averaged responses, with a progressive decrease of $\mathrm{Ca}^{2+}$ and local field potential (LFP) response amplitudes at each inhalation during sustained odorant stimulation (supplemental Fig. $1 \mathrm{~A}$, available at www.jneurosci.org as supplemental material). To take into account this respiration variability, we developed a new averaging algorithm using respiratory movements. For each individual trial, every breathing cycle period was detected and the position of the LFP response onset in the cycle period determined. An averaged breathing signal was then computed from several individuals, and each individual trial was stretched to fit with this average. $\mathrm{Ca}^{2+}$ and LFP responses were then extracted by averaging the trials. Supplemental Figure 1, available at www.jneurosci.org as supplemental material, illustrates that our algorithm allowed maintaining response amplitudes in the averages during prolonged stimulation. These alignments were used to illustrate LFP and $\mathrm{Ca}^{2+}$ responses (see Figs. 2, 3) but not to quantify individual LFP and $\mathrm{Ca}^{2+}$ peaks (see Fig. $2 \mathrm{~B}, \mathrm{C}$ ).

Data analysis. All data were analyzed through a homemade MATLAB program (MathWorks). In the entire study, average values are expressed as mean \pm SEM.

\section{Results}

\section{High concentration of odorant elicits two types of LFP responses in glomeruli}

To trigger ORN adaptation, odorants were applied at high concentrations for $4 \mathrm{~s}$. LFP responses were recorded with fluorescent extracellular glass pipettes targeted in labeled glomeruli with TPLSM. Odorant evoked complex LFP responses with respiration-locked rapid negativities (Fig. 1). We have previously shown that these LFP rapid negativities reflect neuronal postsynaptic activation restricted to a single glomerulus: they are odorant and glomerular specific; they display sharp transitions in space (laterally and in depth), they are blocked by intraglomerular application of ionotropic glutamate antagonists; they are correlated to mitral cell EPSPs (Chaigneau et al., 2007), indicating that mitral cell dendrites participate to their generation. During sustained stimulation at high odorant concentration, we observed two types of LFP responses that differed on their level of adaptation. Note that although the odorant was continuously applied, ORN stimulation was discontinuous because stimulation occurred only at each inhalation every $\sim 0.5 \mathrm{~s}$. Figure $1 \mathrm{~A}$ shows a "weakly adapting response": when the odorant concentration increased, the first negativity, i.e., the initial field EPSP increased and saturated. The following negativities (or peaks) were either maintained or showed a slight decrease in amplitude as the response developed in time. In contrast, some responses strongly adapted with high concentration (from 10 to $100 \%$ of saturated air) (Fig. $1 B$ ). These "strongly adapting responses" were characterized by a large decrease or even an abolition of all the peaks after the initial one. In addition, the slow negative envelop which was crowned by the peaks at low odorant concentration also disappeared. Occasionally, even the first peak amplitude slightly decreased ( 2 of 8 animals). Differences in adaptation level (weak vs strong) occurred between neighboring glomeruli for a given odorant (see below) or in a single glomerulus for two different odorants. Several mechanisms could underlie strongly adapting responses during sustained odorant, e.g., a postsynaptic inhibition of mitral cells involving the glomerular network or a progressive decrease in ORN terminals activation, i.e., a decrease in glutamate release.

\section{Adaptation of $\mathrm{Ca}^{2+}$ influx in olfactory nerve terminals during odor}

To analyze the activation of ORN terminals, we imaged $\mathrm{Ca}^{2+}$ influx in terminals loaded with organic $\mathrm{Ca}^{2+}$ sensors (see Materials and Methods). Labeled terminals outlined glomerular boundaries and allowed to assess the kinetics of odorant-evoked $\mathrm{Ca}^{2+}$ signals (Wachowiak and Cohen, 2001). In single glomeruli ( $n=8$ animals), we simultaneously recorded presynaptic $\mathrm{Ca}^{2+}$ and LFP responses. We therefore investigated the relation between presynaptic and postsynaptic compartments during odorant responses. Figure $2 \mathrm{~A}$ shows a typical example in which presynaptic $\mathrm{Ca}^{2+}$ responses were surprisingly similar to LFP responses. At low odorant concentration, the initial $\mathrm{Ca}^{2+}$ and LFP peaks were similarly larger than the following ones which maintained their amplitude during the stimulus duration. Note that all peaks were phase-locked to respiration. At high odorant concentration, both $\mathrm{Ca}^{2+}$ and LFP responses strongly adapted, the third inhalation peaks being barely detectable. In half of the cases ( 4 of 8 animals), $\mathrm{Ca}^{2+}$ concentration decreased below baseline (Fig. 2, arrow). It was not attributable to photo-bleaching as no rundown was visible before odor and as no decay with time was observable during control experiments (no odorant application; data not shown). It also did not involve changes in respira- 


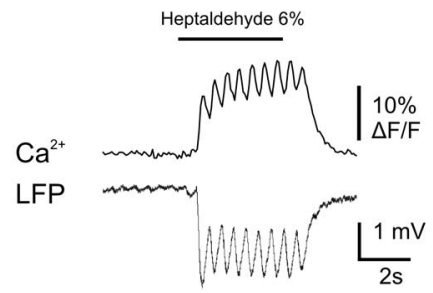

Respiration vrrumrrornm

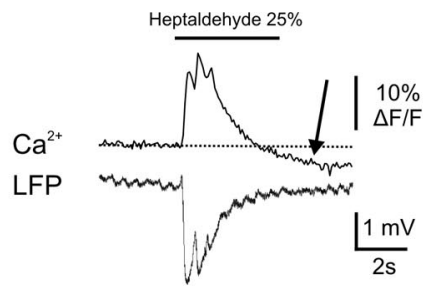

Respiration mrommurmm

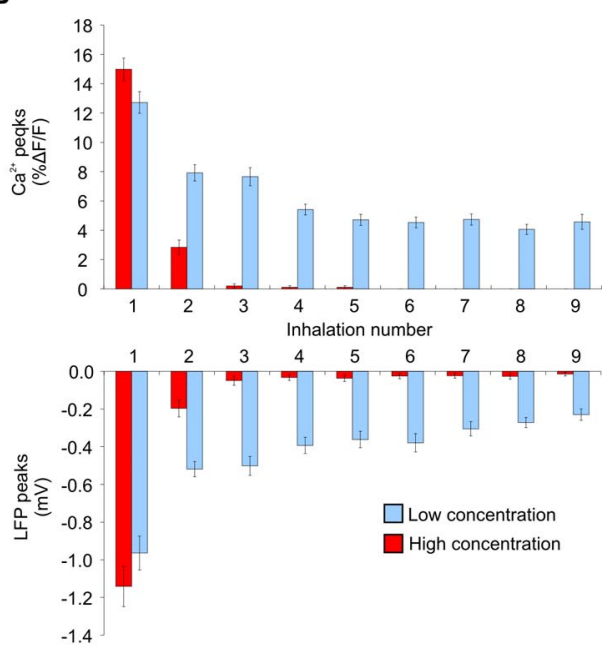

C

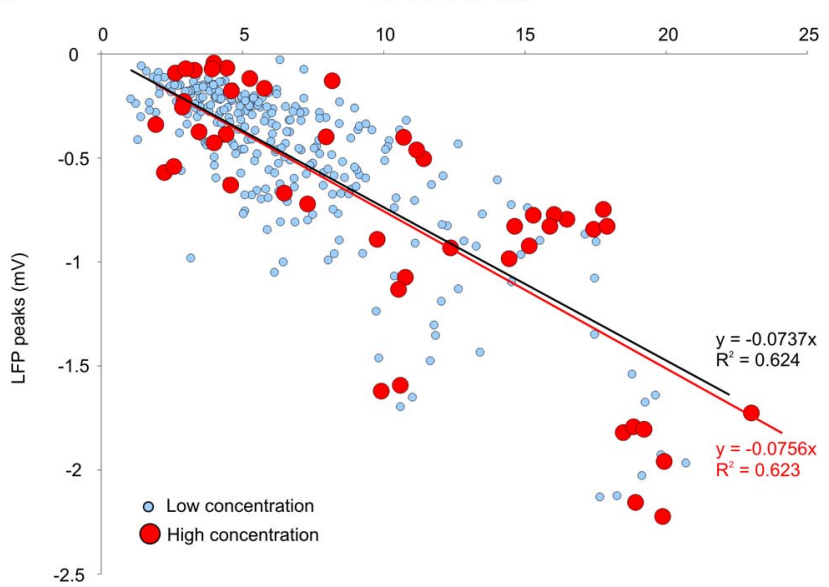

Figure 2. Both calcium $\left(\mathrm{Ca}^{2+}\right)$ and LFP responses show adaptation. $A$, Presynaptic $\mathrm{Ca}^{2+}$ influx in ORNs and LFP were recorded in the same glomerulus. Increasing odorant concentration (bottom traces) strongly shortened both LFP and $\mathrm{Ca}^{2+}$ responses without affecting respiration. Note that in this example, $\mathrm{Ca}^{2+}$ level reversibly decreased below baseline during high odorant concentration (black arrow). $\boldsymbol{B}$, Graphs of $\mathrm{Ca}^{2+}(\Delta F / F$, top traces) and LFP ( $\Delta V$, bottom traces) sniff evoked increments as a function of inhalation numbers, in the presence of an odorant ( $n=8$ animals). $\mathrm{Ca}^{2+}$ and LFP peak values are raw data (i.e., without averaging or stretching) measured for each inhalation. At low odorant concentration (blue bars), $\mathrm{Ca}^{2+}$ and LFP peak amplitudes were maintained, although they disappeared within two inhalations at high odorant concentration (red bars). C, The input ( $\mathrm{Ca}^{2+}$ peaks) - output (LFP peaks) relationship was not affected by odorant concentration and adaptation, as shown by the perfect overlap of the two linear regression curves. Regression lines were drawn from all evoked responses in eight animals for low and high odorant concentrations.

tion frequency. To quantify adaptation at both presynaptic and postsynaptic levels, we measured on each individual trace (i.e., without averaging or stretching; see Materials and Methods) the peak amplitude of $\mathrm{Ca}^{2+}(\Delta F / F$ increment) (Fig. $2 B$, top) and LFP ( $\Delta V$ increment) (Fig. $2 B$, bottom) signals at each inhalation. At low concentration, $\mathrm{Ca}^{2+}$ and LFP peaks decreased after the initial one but then remained similarly constant during most of the odorant application (4s). At high concentration, $\mathrm{Ca}^{2+}$ and LFP peaks disappeared after the second inhalation but in one case (out of 8) persisted during five inhalations. The average delay between the first peak and the first inhalation without any response was $1.04 \pm 0.14 \mathrm{~s}(n=8)$, indicating that after only two inhalations, little glomerular excitatory output was sent to mitral cell somata. Because LFP responses mirrored adapting $\mathrm{Ca}^{2+}$ signals and, in some cases (see Fig. 4A), adaptation already occurred on the initial $\mathrm{Ca}^{2+}$ peak, dye saturation could not account for adaptation of fluorescence signals. Overall, these results suggest that glomerular LFP adaptation is associated with a concentration- and timedependent adaptation of $\mathrm{Ca}^{2+}$ influx in ORN terminals and most probably from a decrease in glutamate release.

\section{The glomerular input-output curve}

The two graphs in Figure $2 B$ indicate that presynaptic and postsynaptic responses were highly correlated. To determine whether this correlation was sensitive to odorant concentration, we plotted LFP peaks as a function of presynaptic $\mathrm{Ca}^{2+}$ peaks (Fig. 2C), i.e., the input-output curve of all recorded glomeruli. At both low and high odorant concentration, the linear regression curves surprisingly overlapped, indicating that $\mathrm{Ca}^{2+}$ peaks are excellent markers of LFP peaks, which are themselves highly correlated to EPSPs recorded in mitral cells (Chaigneau et al., 2007). The perfect overlap of the two linear regression curves also indicates that LFP adaptation does not involve a postsynaptic mechanism. It involves either a presynaptic inhibition of ORN terminals or an ORN adaptation at the nasal epithelium level. Presynaptic inhibition regulates glutamate release at ORN terminals (Hsia et al., 1999; Wachowiak and Cohen, 1999; Aroniadou-Anderjaska et al., 2000; Ennis et al., 2001; Olsen and Wilson, 2008) by decreasing $\mathrm{Ca}^{2+}$ influx in the terminals (Wachowiak and Cohen, 1999; McGann et al., 2005; Vucinić et al., 2006; Pírez and Wachowiak, 2008). To investigate the role of presynaptic inhibition in glomerular adaptation, we tested the effects of local application of antagonists of ionotropic glutamate receptors and $\mathrm{GABA}_{\mathrm{B}}$ receptors on ORN terminals $\mathrm{Ca}^{2+}$ responses.

\section{Fast peripheral adaptation, and not presynaptic inhibition, underlies glomerular adaptation}

We have shown previously that odorantevoked local LFP responses are abolished by focal applications of NBQX and D-APV, antagonists of glutamate AMPA and NMDA receptors, respectively (Chaigneau et al., 2007). Here, we coapplied Alexa Fluor 594 and glutamate antagonists (NBQX, $250 \mu \mathrm{M}$; $\mathrm{D}$-APV , $500 \mu \mathrm{M})$ through the LFP recording pipette and maintained the pipette pressure until the drug diffused into the entire glomerular and periglomerular boundaries, ensuring that we blocked all intraglomerular and interglomerular glutamatergic synaptic inputs. Glutamate antagonists reversibly blocked the local LFP response, i.e., the LFP peaks and part of the slow component (Fig. $3 A, B$ ). Note that the remaining slow component was not locally generated because it persists in the external plexiform layer (Chaigneau et al., 2007) and reverses its polarity in the granule cell layer (E. Chaigneau and S. Charpak, unpublished data), thus reflecting the activation of granule cells. In contrast, NBQX/D-APV reversibly enhanced presynaptic $\mathrm{Ca}^{2+}$ responses evoked by both low and high odorant concentrations. Glutamate 
antagonists increased the initial $\mathrm{Ca}^{2+}$ peak to $126 \%$ of control $\mathrm{CCa}^{2+}$ peak (percentage of $\Delta F / F]$ : control, $15.30 \pm 3.15$; NBQX/D-APV, $19.39 \pm 3.33$; recovery, $15.24 \pm 3.26 ; n=8 ; p=0.013$ ) as well as the overall $\mathrm{Ca}^{2+}$ signal (area) to $119 \%$ of control $\left[\mathrm{Ca}^{2+}\right.$ area (arbitrary units, a.u.) ]: control, $37.34 \pm 5.69$; NBQX/D-APV, $44.58 \pm 6.45$; recovery, $36.11 \pm 5.95 ; n=$ $8 ; p=0.009)$. These results confirm, although under different anesthesia conditions (Pírez and Wachowiak, 2008), that tonic presynaptic inhibition modulates odorant-evoked $\mathrm{Ca}^{2+}$ signals in ORN terminals and as a consequence the glomerular output. Note that the increase of presynaptic $\mathrm{Ca}^{2+}$ (area) by NBQX/D-APV was similar for odorant stimulations at low and high concentration $(117 \pm 7 \%$ and $125 \pm 9 \%$, respectively; $p=0.54)$. This further suggests that glomerular adaptation results from tonic inhibition rather than from odorant-evoked presynaptic inhibition. Similarly, local application of the $\mathrm{GABA}_{\mathrm{B}}$ receptor antagonist CGP35348 (1-10 mm) (Fig. 3C) also increased the overall signal $\left[\mathrm{Ca}^{2+}\right.$ area (a.u.)]: control, $22.86 \pm 2.15$; CGP35348, $27.97 \pm 2.20$; $n=8 ; p=0.01$ ), indicating that presynaptic tonic inhibition involved $\mathrm{GABA}_{\mathrm{B}}$ receptors (Pírez and Wachowiak, 2008). In contrast to presynaptic $\mathrm{Ca}^{2+}$ signals, LFP responses were either maintained or slightly decreased (data not shown) on CGP35348, suggesting that $\mathrm{GABA}_{\mathrm{B}}$ receptors are involved at both presynaptic and postsynaptic sites, and their activation induces a complex modulation of the glomerular network activity. More importantly, blockade of presynaptic inhibition did not significantly affect the adaptation of $\mathrm{Ca}^{2+}$ influx. $\mathrm{Ca}^{2+}$ responses to low odorant concentration in control conditions continued to be significantly larger than responses to high odorant concentration in the absence of presynaptic inhibition. The general shape of $\mathrm{Ca}^{2+}$ responses was not modified by glutamate or $\mathrm{GABA}_{\mathrm{B}}$ receptor antagonists, implying that in urethane anesthetized animals, peripheral adaptation of ORNs underlies the glomerular adaptation that occurs during high odorant concentration.

\section{Peripheral adaptation modulates glomerular maps}

What are the consequences of peripheral adaptation on glomerular maps? TPLSM imaging of large fields of view comprising several glomeruli, with a lower temporal resolution, allowed assessing the spread of odor-evoked $\mathrm{Ca}^{2+}$ signals with odorant concentration. Figure $4, A$ and $B$, illustrate two experiments where several neighboring glomeruli were activated by an odorant. At low concentration, odor evoked a rapid $\mathrm{Ca}^{2+}$ response in a single glomerulus (Fig. $4 A, B$, traces), confirming the glomerular specificity of odorant stimulation at low concentration. The $\mathrm{Ca}^{2+}$ response had a sustained plateau-like shape, showing little attenuation during the $4 \mathrm{~s}$ stimulation. Note that the absence of $\mathrm{Ca}^{2+}$ peaks resulted from the low temporal resolution, each image lasting $200 \mathrm{~ms}$. In each "odorant specific" glomerulus, increasing the odor concentration drastically shortened the plateau-like response observed at low concentration (Fig. $4 A, B$,
C

\section{Single experiment}

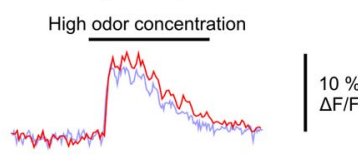

Normalised average

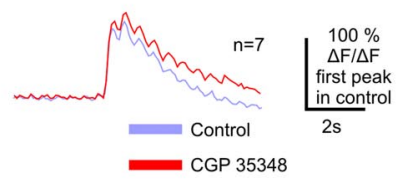

D

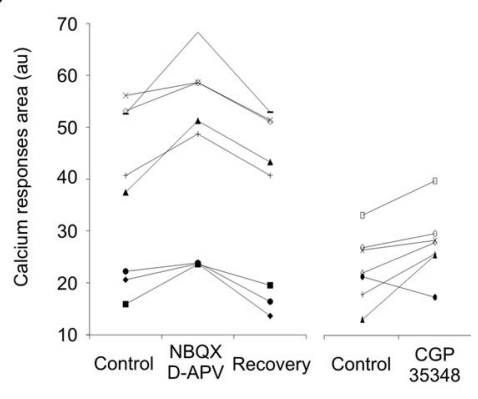

Figure 3. In vivo blockade of postsynaptic activity reveals peripheral ORN adaptation. $A, B$, Simultaneous recordings of preaveraged $(\boldsymbol{B})$ responses ( $n=8$ animals) revealed that glutamate antagonists reversibly blocked LFP responses and increased $\mathrm{Ca}^{2+}$ peak amplitudes. The first $\mathrm{Ca}^{2+}$ peak was also increased, indicating tonic presynaptic inhibition. NBQX/D-APV barely tonic presynaptic inhibition is mediated through $\mathrm{GABA}_{B}$ receptors but not responsible of adaptation at high odorant concentration. D, Summary graphs showing the effects of NBQX/D-APV and CGP35348 on $\mathrm{Ca}^{2+}$ responses.

traces in red) and even decreased, in some cases, the initial amplitude (Fig. $4 A$ ). In contrast, high odorant concentration recruited neighboring glomeruli, which showed little adaptation of $\mathrm{Ca}^{2+}$ responses. Such spatial redistribution of activated glomeruli was observed in all tested animals $(n=5)$. The graph in Figure $4 C$ quantifies this effect on three groups of glomeruli $(n=11$ glomeruli), which were tested for at least 3-4 odorant concentrations. In each group, one glomeruli showed a marked $\mathrm{Ca}^{2+}$ response decrease at high odorant concentration (red traces). These results show that because of peripheral adaptation, the relative glomerular output of a "specific" glomerulus (responsive to low odorant concentration) versus its neighbors changes drastically at high odor concentration.

\section{Discussion}

Peripheral adaptation depends on $\mathrm{Ca}^{2+}$ influx in ORNs and as a consequence on odorant concentration. Spatial maps of glomerular activity vary with odorant concentration; however, most of the variability is assigned to the low specificity of odorant receptors. Here, we investigated under which conditions odor could modulate glomerular activation through a mechanism involving peripheral adaptation. We specifically analyzed postsynaptic glomerular responses that expressed strong adaptation under high odorant concentration. We found that glomerular adaptation resulted from a decrease in ORN terminals activation, i.e., in glutamate release, which did not involve local presynaptic inhibition. Our study, thus, indirectly demonstrates that peripheral adaptation of ORNs underlies glomerular adaptation, without hypothesizing which peripheral adaptation processes are involved. Direct demonstration would require firing measure- 
A
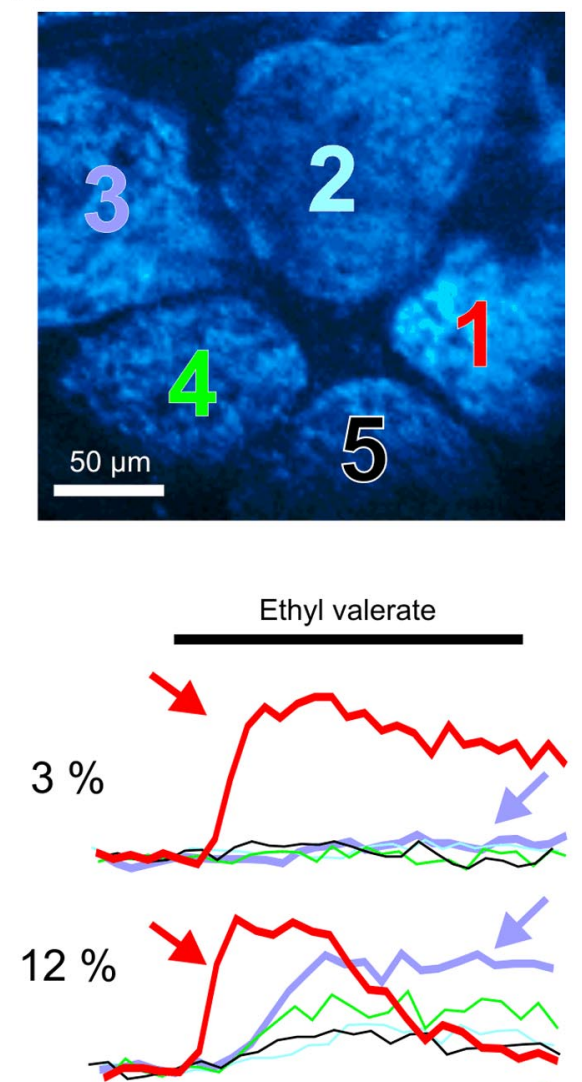

$37 \%$

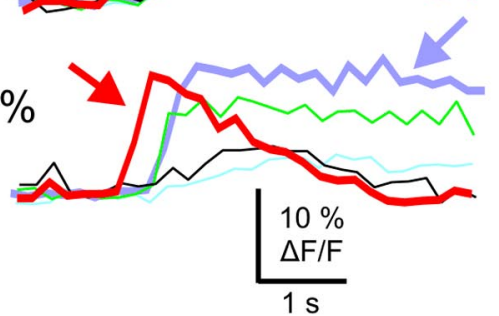

B

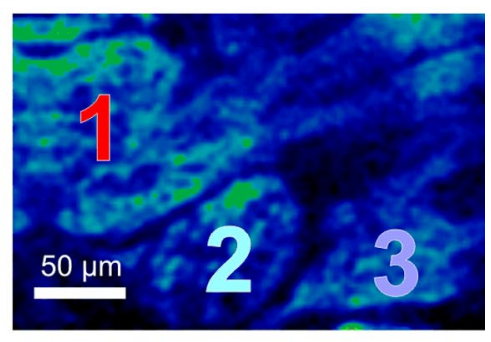

Hexanal
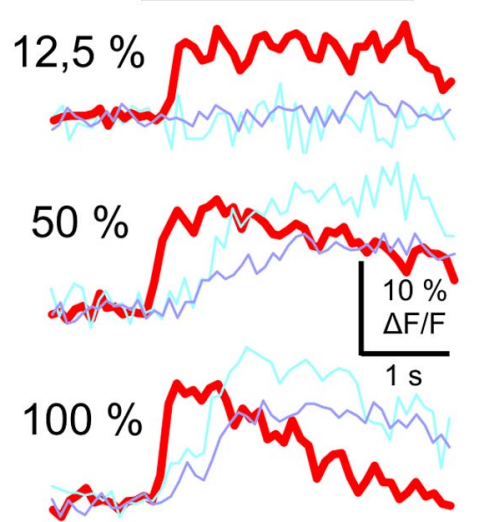

C

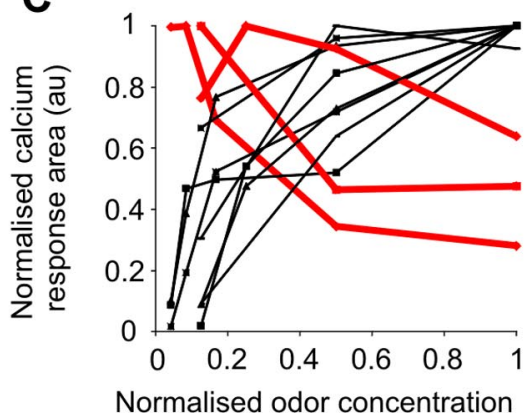

Figure 4. Peripheral adaptation causes a spatial redistribution of activated glomeruli. $\boldsymbol{A}, \boldsymbol{B}$, Top, Two-photon imaging of two large fields of view comprising five $(\boldsymbol{A})$ and three $(\boldsymbol{B})$ glomeruli. ORN terminals were labeled with $\mathrm{Ca}^{2+}$ green dextran $(10 \mathrm{kDa}) . \boldsymbol{A}$, Bottom, Glomeruli presented two types of $\mathrm{Ca}^{2+}$ responses according to the odorant concentration. At low concentration, ethyl valerate evoked a rapid $\mathrm{Ca}^{2+}$ plateau (red arrow) in glomerulus 1, although it did not affect neighboring glomeruli (2-5). Raising the odorant concentration shortened the $\mathrm{Ca}^{2+}$ response of glomerulus 1 , although it revealed those of glomeruli $2-5$. Note the appearance of a $\mathrm{Ca}^{2+}$ plateau in glomerulus 2 (blue arrow). $\boldsymbol{B}$, Bottom, Another case where the most sensitive glomerulus (glomerulus 1) shows a $\mathrm{Ca}^{2+}$ response adaptation. C, Quantification of $\mathrm{Ca}^{2+}$ signal adaptation. The overall $\mathrm{Ca}^{2+}$ responses (area) were normalized and plotted as a function of the odorant concentration (normalized to its maximum value) for three groups of glomeruli (11 glomeruli, three animals). Peripheral adaptation greatly reduced $\mathrm{Ca}^{2+}$ responses of the three most sensitive glomeruli (red traces), whereas responses of the neighboring glomeruli increased (black traces).

ments of targeted axons converging in an adapting glomerulus. Such tour de force is not necessary because reported ORN properties fully account for glomerular adaptation. In addition, our pharmacological experiments confirm the existence of a tonic presynaptic inhibition of ORN terminals (Petzold et al., 2008; Pírez and Wachowiak, 2008). They also show that at high odorant concentration, peripheral adaptation widely dominates evokedpresynaptic inhibition.

We believe that the observed adaptation is a general mechanism that simply depends on the level of ORN activation. As a consequence, we postulate that odorant stimulation of increasing intensity will first increase and then progressively shorten specific glomerular responses such that at high concentration, only the first few inhalations will transmit information to second-order neurons. In contrast, the surrounding less specific glomeruli will become more active and relay peripheral information. $\mathrm{Al}-$ though LFP negativities strictly indicate what glomerular output (EPSPs) is transmitted to mitral/tufted cell somata, and gives no quantitative indication on the spiking output to the cortex, we hypothesize that peripheral adaptation is a major modulatory determinant of mitral/tufted cell firing during strong odorant stimulation. The validation of our hypothesis will require challenging experiments to measure mitral/tufted cell activity, first none invasively (in cell attached mode) and to extract in a second step (in whole-cell mode) the respective weights of peripheral adaptation and lateral inhibition in shaping the spiking output. It is also important to stress that the persistence of an odor response during the first inhalation remains compatible with the ability to discriminate odors. Indeed, recent studies have demonstrated that discrimination tasks can be achieved within few hundred milliseconds (Uchida and Mainen, 2003; Abraham et al., 2004; Rinberg et al., 2006; Slotnick, 2007). In fact, it has been shown that successful odor discrimination occurs before full development of the first inhalation glomerular map (Wesson et al., 2008). In addition to coding of high odor concentration, the fast peripheral adaptation underlying glomerular adaptation could increase the dynamic range of glomerular activation. Such a role had been proposed but not observed for evoked-presynaptic inhibition (Pírez and Wachowiak, 2008) and is classically reported at the level of ORN transduction (for review, see Kleene, 2008).

\section{References}

Abraham NM, Spors H, Carleton A, Margrie TW, Kuner T, Schaefer AT (2004) Maintaining accuracy at the expense of speed: stimulus similarity defines odor discrimination time in mice. Neuron 44:865-876.

Aroniadou-Anderjaska V, Zhou FM, Priest CA, Ennis M, Shipley MT (2000) Tonic and synaptically evoked presynaptic inhibition of sensory input to the rat olfactory bulb via GABA(B) heteroreceptors. J Neurophysiol 84:1194-1203.

Bakalyar HA, Reed RR (1990) Identification of a specialized adenylyl cyclase that may mediate odorant detection. Science 250:1403-1406.

Borisy FF, Ronnett GV, Cunningham AM, Juilfs D, Beavo J, Snyder SH (1992) Calcium/calmodulin-activated phosphodiesterase expressed in olfactory receptor neurons. J Neurosci 12:915-923.

Bradley J, Reisert J, Frings S (2005) Regulation of cyclic nucleotide-gated channels. Curr Opin Neurobiol 15:343-349.

Buck L, Axel R (1991) A novel multigene family may encode odorant receptors: a molecular basis for odor recognition. Cell 65:175-187.

Chaigneau E, Tiret P, Lecoq J, Ducros M, Knöpfel T, Charpak S (2007) The relationship between blood flow and neuronal activity in the rodent olfactory bulb. J Neurosci 27:6452-6460.

Duchamp-Viret P, Duchamp A, Chaput MA (2000) Peripheral odor coding 
in the rat and frog: quality and intensity specification. J Neurosci 20:2383-2390.

Duchamp-Viret P, Duchamp A, Chaput MA (2003) Single olfactory sensory neurons simultaneously integrate the components of an odour mixture. Eur J Neurosci 18:2690-2696.

Ennis M, Zhou FM, Ciombor KJ, Aroniadou-Anderjaska V, Hayar A, Borrelli E, Zimmer LA, Margolis F, Shipley MT (2001) Dopamine D2 receptormediated presynaptic inhibition of olfactory nerve terminals. J Neurophysiol 86:2986-2997.

Hsia AY, Vincent JD, Lledo PM (1999) Dopamine depresses synaptic inputs into the olfactory bulb. J Neurophysiol 82:1082-1085.

Jones DT, Reed RR (1989) Golf: an olfactory neuron specific-G protein involved in odorant signal transduction. Science 244:790-795.

Kleene SJ (2008) The electrochemical basis of odor transduction in vertebrate olfactory cilia. Chem Senses 33:839-859.

Kurahashi T, Menini A (1997) Mechanism of odorant adaptation in the olfactory receptor cell. Nature 385:725-729.

Leinders-Zufall T, Ma M, Zufall F (1999) Impaired odor adaptation in olfactory receptor neurons after inhibition of $\mathrm{Ca}^{2+} /$ calmodulin kinase II. J Neurosci 19:RC19.

Lowe G, Gold GH (1993) Nonlinear amplification by calcium-dependent chloride channels in olfactory receptor cells. Nature 366:283-286.

Matthews HR, Reisert J (2003) Calcium, the two-faced messenger of olfactory transduction and adaptation. Curr Opin Neurobiol 13:469-475.

McGann JP, Pírez N, Gainey MA, Muratore C, Elias AS, Wachowiak M (2005) Odorant representations are modulated by intra- but not interglomerular presynaptic inhibition of olfactory sensory neurons. Neuron 48:1039-1053.

Mori K, Takahashi YK, Igarashi KM, Yamaguchi M (2006) Maps of odorant molecular features in the mammalian olfactory bulb. Physiol Rev 86:409-433.

Nakamura T, Gold GH (1987) A cyclic nucleotide-gated conductance in olfactory receptor cilia. Nature 325:442-444.

Olsen SR, Wilson RI (2008) Lateral presynaptic inhibition mediates gain control in an olfactory circuit. Nature 452:956-960.

Petzold GC, Albeanu DF, Sato TF, Murthy VN (2008) Coupling of neural activity to blood flow in olfactory glomeruli is mediated by astrocytic pathways. Neuron 58:897-910.

Pifferi S, Boccaccio A, Menini A (2006) Cyclic nucleotide-gated ion channels in sensory transduction. FEBS Lett 580:2853-2859.

Pírez N, Wachowiak M (2008) In vivo modulation of sensory input to the olfactory bulb by tonic and activity-dependent presynaptic inhibition of receptor neurons. J Neurosci 28:6360-6371.
Rinberg D, Koulakov A, Gelperin A (2006) Speed-accuracy tradeoff in olfaction. Neuron 51:351-358.

Schaefer AT, Margrie TW (2007) Spatiotemporal representations in the olfactory system. Trends Neurosci 30:92-100.

Schafer JR, Kida I, Rothman DL, Hyder F, Xu F (2005) Adaptation in the rodent olfactory bulb measured by fMRI. Magn Reson Med 54:443-448.

Slotnick B (2007) Odor-sampling time of mice under different conditions. Chem Senses 32:445-454.

Sobel N, Khan RM, Hartley CA, Sullivan EV, Gabrieli JD (2000) Sniffing longer rather than stronger to maintain olfactory detection threshold. Chem Senses 25:1-8.

Spors H, Grinvald A (2002) Spatio-temporal dynamics of odor representations in the mammalian olfactory bulb. Neuron 34:301-315.

Spors H, Wachowiak M, Cohen LB, Friedrich RW (2006) Temporal dynamics and latency patterns of receptor neuron input to the olfactory bulb. J Neurosci 26:1247-1259.

Uchida N, Mainen ZF (2003) Speed and accuracy of olfactory discrimination in the rat. Nat Neurosci 6:1224-1229.

Vucinić D, Cohen LB, Kosmidis EK (2006) Interglomerular centersurround inhibition shapes odorant-evoked input to the mouse olfactory bulb in vivo. J Neurophysiol 95:1881-1887.

Wachowiak M, Cohen LB (1999) Presynaptic inhibition of primary olfactory afferents mediated by different mechanisms in lobster and turtle. J Neurosci 19:8808-8817.

Wachowiak M, Cohen LB (2001) Representation of odorants by receptor neuron input to the mouse olfactory bulb. Neuron 32:723-735.

Wachowiak M, Shipley MT (2006) Coding and synaptic processing of sensory information in the glomerular layer of the olfactory bulb. Semin Cell Dev Biol 17:411-423.

Wei J, Zhao AZ, Chan GC, Baker LP, Impey S, Beavo JA, Storm DR (1998) Phosphorylation and inhibition of olfactory adenylyl cyclase by CaM kinase II in neurons: a mechanism for attenuation of olfactory signals. Neuron 21:495-504.

Wesson DW, Carey RM, Verhagen JV, Wachowiak M (2008) Rapid encoding and perception of novel odors in the rat. PLoS Biol 6:e82.

Wilson DA (1998) Synaptic correlates of odor habituation in the rat anterior piriform cortex. J Neurophysiol 80:998-1001.

Wilson DA, Linster C (2008) Neurobiology of a simple memory. J Neurophysiol 100:2-7.

Yan C, Zhao AZ, Bentley JK, Loughney K, Ferguson K, Beavo JA (1995) Molecular cloning and characterization of a calmodulin-dependent phosphodiesterase enriched in olfactory sensory neurons. Proc Natl Acad Sci U S A 92:9677-9681. 